\title{
The Influence of Tourists' Attitude and Self-efficacy Belief in Adopting Responsible Behavior in Bangladesh
}

\author{
Md. Shahzalal \\ Begum Rokeya University, Rangpur, Bangladesh
}

\begin{abstract}
This research examined tourists' intention to adopt responsible behavior (RB). Toward this, two constructs of determinants (attitude and self-efficacy belief) of intention to adopt RB were identified through literature surveys. Also, three constructs of RB alternatives, namely, economically RB (ECNRB), environmentally RB (ENVRB), and socio-culturally RB (SCLRB), were identified through a focus group discussion. A self-administrated questionnaire was surveyed among 351 professionals in Bangladesh. Confirmatory factor analysis of both the independent and dependent variables was done prior to employing them in the structured equation model to validate the model and test the hypotheses. The research found that in Bangladesh, the self-efficacy belief influences tourists' intention to choose RB more than the attitude does, but their influences on tourists' intention to adopt ECNRB, ENVRB, or SCLRB are varied. Moreover, tourists were found to have less intention to adopt ECNRB than ENVRB and SCLRB. For the policy makers or promoters of responsible tourism (RT), those who want to promote any kind of RB in Bangladesh need to increase self-efficacy belief among tourists. The policy makers need to develop themes around tourists' positive experience, emotional and physiological states along with verbal persuasion in their communication messages (Bandura, 1997) and in any kind of interpretations at the destination whilst targeting a particular market segment.
\end{abstract}

Keywords: responsible tourist behavior (RTB), attitude, self-efficacy belief, structured equation modeling, focus group, environment, economic

\section{Introduction}

"Responsible tourism is not a tourism product or a brand" (Husbands \& Harrison, 1996, p. 1) rather than it is a behavioral trait that applies to all the stakeholders in tourism (Leslie, 2012a). It is about taking responsibility for the consequences of one's own actions whilst engaging with tourism (Goodwin, 2011). As tourists stay in the center of the tourism phenomenon (Burns, 2000), they have serious accountability or responsibility in tourism, including travelling in a better way and minimizing the impacts of their actions on a destination community (Goodwin \& Pender, 2005). More specifically, responsible tourists "actively seek out holidays that allow them to show respect for local communities, enable them to share the economic benefits of tourism directly with local people, and want to mitigate any environmental impact" (Weeden, 2014, p. 43). To understand responsible tourist behavior (RTB) properly, two key things need to be understood clearly. First, tourists' behavioral intention, because intention directs actual behavior (Mathur, 1998). Tourists' own thought for being more responsible (attitude) and the belief that their own behavior can make a difference (self-efficacy) affect their behavioral intention (Doran, Hanss, \& Larsen, 2015).

Md. Shahzalal, Assistant Professor, Department of Marketing, Begum Rokeya University. Email: shahzalalstar@gmail.com. 
The second thing is the dimensions of tourists' responsibility, because responsibility has its environmental, economic, and social-cultural dimensions (Cape Town Conference, 2002). Tourists' environmentally responsible behavior (ENVRB) refers to contributing to protecting and conserving wildlife, marine habitats, and built environment (Hudson \& Ritchie, 2001; Ballantyne, Packer, \& Hughes, 2009). Their economically responsible behavior (ECNRB) includes searching for in where and on what they should spend (Atkins, 2010) to benefit the local economy (Tearfund, 2000a). Moreover, tourists' socio-culturally responsible behavior (SCLRB) includes appreciating and protecting local history, traditions, and cultural uniqueness (Tixier, 2010), and respecting community values as well as a local identity (O'Sullivan \& Jackson, 2002).

There are more responsible tourists in developed countries (e.g., EU, USA, and Australia) than in developing countries (SNV, 2011), who are willing to pay more and are concerned about social, economic, environmental, and cultural responsibilities (Chafe, 2005; Budeanu, 2007). The tourists in developing countries think their responsibilities differently than in developed countries (Cater, 1993) and influence negatively the destinations' total environment (Som, Marzuki, Yousefi, \& AbuKhalifeh, 2012). However, the host population cannot afford the protection costs of the cultural and natural environment in those destinations in developing countries (Cater, 1993). So, in developing countries, a paradigm shift in tourist behavior is badly needed (Sharpley, 2010) to encourage a domestic tourist to be a catalyst for local protection (Jarvis, 2013). Considering the above circumstances, to generate insights into tourists' intention to choose RB, this study was undertaken in a developing country. The domestic tourists of Bangladesh were selected as a study case. In this country, no mentionable research on RTB was conducted before (Zahra, 2013).

This research first aimed at defining tourists' RB from contemporary literature, then identified a set of attitude and self-efficacy belief related determinants through a literature survey. It also aimed at identifying a set of ECNRB, ENVRB, and SCLRB practices in Bangladesh. Finally, the researcher wanted to explain which one of the two determinants influences tourists' intention more than another to adopt a particular RB through a relevant statistical analysis of the surveyed data.

\section{Literature Review}

\section{Responsible Tourism (RT) and the RTB}

Although tourist is the primary actor in a range of tourism-related actors (Grimwood, Yudina, Muldoon, \& Qiu, 2015) to date, a limited research has been conducted on the responsibilities and obligations of tourists (Moscardo, Konovalov, Murphy, \& McGehee, 2013). At the Cape Town Conference (2002), RT was introduced as a tool to minimize negative impacts on destination community, generate economic benefits for the locals, involve stakeholders in decision-making, conserve local natural and cultural heritage, and provide meaningful connections between the hosts and guests. Tourists' underlying drivers formulate how they consume and constitute RT (Caruana, Glozer, Crane, \& McCabe, 2014). For example, responsible tourists themselves define responsibility as to be morally concerned for individual, community, social, and environmental well-being (Leslie, 2012b) or to become responsible for "not leaving a trace" or to make a low impact travel or to take care of the places to visit (Grimwood et al., 2015), or to reduce risk for and respect the local people (Simon \& Alagona, 2009). Table 1 presents a summary of the characteristics of RTB found in the contemporary literatures. 
Table 1

\section{A Summary of the Characteristics of RTB as Found in the Contemporary Literatures}

\begin{tabular}{|c|c|}
\hline Source & Characteristic \\
\hline $\begin{array}{l}\text { Tearfund } \\
\text { (2000a; 2000b) }\end{array}$ & $\begin{array}{l}\text { 1. Find out about the destination } \\
\text { 2. Learn basics of the local language } \\
\text { 3. Buy locally made goods and use locally provided services } \\
\text { 4. Avoid conspicuous displays of wealth } \\
\text { 5. Minimize environmental impact } \\
\text { 6. Slow down to enjoy the differences (Tearfund, 2000a) } \\
\text { 7. Ask permission before taking photographs of people } \\
\text { 8. Learn about and honor local customs (Tearfund, 2000b) } \\
\text { 9. Pay a fair price for the goods or services } \\
\text { 10. Be sensitive to the locals }\end{array}$ \\
\hline Lea (1993) & $\begin{array}{l}\text { 1. Understand the local culture } \\
\text { 2. Tread softly on the hosts' environment } \\
\text { 3. Respect and be sensitive to the hosts }\end{array}$ \\
\hline Mann (2000, p. 201) & Treat local people as people - not as beggars, nuisances, con men, thieves, or exotic photo opportunities \\
\hline \multirow{3}{*}{ CREST (2009, p. 36) } & $\begin{array}{l}\text { A. Interactive: } \\
\text { (1) Interact with and learn about the natural, social, and cultural environment } \\
\text { (2) Meet and interact with locals } \\
\text { (3) Participate in the lifestyles and experience it, rather than observe it } \\
\text { (4) Develop relationships with other tourists and locals }\end{array}$ \\
\hline & $\begin{array}{l}\text { B. Experimental: } \\
\text { (1) Explore authentic personal experiences, self-discovery, and growth } \\
\text { (2) Expose to unique and compelling experiences }\end{array}$ \\
\hline & $\begin{array}{l}\text { C. Social and environmental consciousness: } \\
\text { (1) Minimize impact on the destination } \\
\text { (2) Support environmental conservation } \\
\text { (3) Conserve energy and water, and minimize waste } \\
\text { (4) Patronize local economy (businesses owned by locals or that employ local people) } \\
\text { (5) Behave and dress appropriately } \\
\text { (6) Be less materialistic } \\
\text { (7) Stay longer and spend more }\end{array}$ \\
\hline Chafe (2005) & $\begin{array}{l}\text { 1. Take some education and collect information on the destination } \\
\text { 2. Be conscious of social and cultural aspects and environmental impact } \\
\text { 3. Explore authenticity and pristineness } \\
\text { 4. Pay more if possible }\end{array}$ \\
\hline $\begin{array}{l}\text { Weeden } \\
(2014, \text { pp. 71-72). }\end{array}$ & $\begin{array}{l}\text { 1. Prefer to travel independently } \\
\text { 2. Like to buy locally made souvenirs and patronize locally owned shops and restaurants } \\
\text { 3. Make an effort to learn local language } \\
\text { 4. Use public transports } \\
\text { 5. Like outdoors, enjoy nature } \\
\text { 6. Walk around the countryside } \\
\text { 7. Want to meet new people } \\
\text { 8. Observe cultural norms relating to dress and behavior } \\
\text { 9. Prefer to stay in a locally owned accommodation, family run hotel, eco-cabin, guesthouse, or camping } \\
\text { on an organic farm }\end{array}$ \\
\hline Caruana et al. (2014) & $\begin{array}{l}\text { 1. Instrumental opportunism: Show a low level of involvement and an extrinsic goal direction for } \\
\text { responsible tourism } \\
\text { 2. Mindful minimizing: Show a high level of involvement and an extrinsic goal direction } \\
\text { 3. Educational empathy: Show a low level of involvement and an intrinsic goal direction } \\
\text { 4. Conscious advocating: Show a high level of involvement and an intrinsic goal direction }\end{array}$ \\
\hline
\end{tabular}

Reviewing all the above characteristics of RTB, it can be broadly defined that:

Responsible tourists meet and interact with local people, local culture, and fellow tourists; explore authenticity by employing mental and physical efforts, keep no negative trace on local natural and cultural environment, patronize local economy, learn local language, treat local people as normal and pay fair prices of their hospitality. 


\section{Context}

In Bangladesh, from a recent study, it was found that in the most attractive and visited destination (Cox's Bazar - the world's longest sea beach), the destination community is being severely affected by the negative socio-economic and environmental impacts, including excessive crowds, littering, security, and social problems that are mainly caused by the domestic tourists (Zahra, 2013). Bangladesh mainly offers nature and cultural based tourism (Hassan \& Shahnewaz, 2014). An increasing number of domestic holiday makers from the big domestic market are traveling in groups and seeking rest or relax (Parveen, 2013) and entertainment, new experience, natural beauty, and landscape (Honeck \& Akhtar, 2014; Ferdaush \& Faisal, 2014) that is creating excessive pressure on the destination communities.

\section{Attitude and Self-efficacy Belief in Adopting Responsible Behavior}

In a recent study, attitude was found to have a positive influence on tourists' intention to adopt RB (Untaru, Epuran, \& Ispas, 2014). Attitude is an individual evaluation of the possibilities to perform a task (Wurzinger, 2003) or in other words, it is a modifier of behavioral intentions (Schultz \& Oskamp, 1996). Attitude has a high correlation with intentions or estimates when the choice of alternatives is given (Sheppard, Hartwick, \& Warshaw, 1988). For example, it was found as a major predictor of intention to stay at a green hotel (Han, Hsu, \& Sheu, 2010) and a better predictor of future behavior of tourists (Lee, 2009). So, one hypothesis for the research was proposed:

H1: Tourists' attitude is the most influential determinant of their intention to adopt RB.

In addition to attitude, self-efficacy belief is a major determinant of intention to choose any behavior that is new or difficult to perform (Ben-Ami, Hornik, Eden, \& Kaplan, 2014). Self-efficacy is a kind of belief of how well one can execute a course of action using his/her capacity (Bandura, 1997), which is sometimes perceived as an internal resource (Fishbein \& Ajzen, 2010). This resource may include "ability, talent, knowledge, skill, endurance and willpower" (Ben-Ami et al., 2014, p. 1915). As it determines the feeling of ease or difficulty in a given situation (Bay \& Daniel, 2003), it can predict the intention to adopt behavior in that given circumstance. So, another hypothesis for this research was proposed:

H2: Tourists' self-efficacy belief is the most influential determinant of their intention to adopt RB.

Moreover, some contemporary behavioral researchers in tourism found that one of the antecedents (determinants) might have more influence on intention than others (Bagozzi \& Warshaw, 1990; Xie, Bagozzi, \& Troye, 2008; Sandve, Marnburg, \& Øgaard, 2014). So, the researcher wanted to test one more hypothesis:

H3: The influence of attitude and self-efficacy belief is varied in predicting ECNRB, ENVRB, and SCLRB.

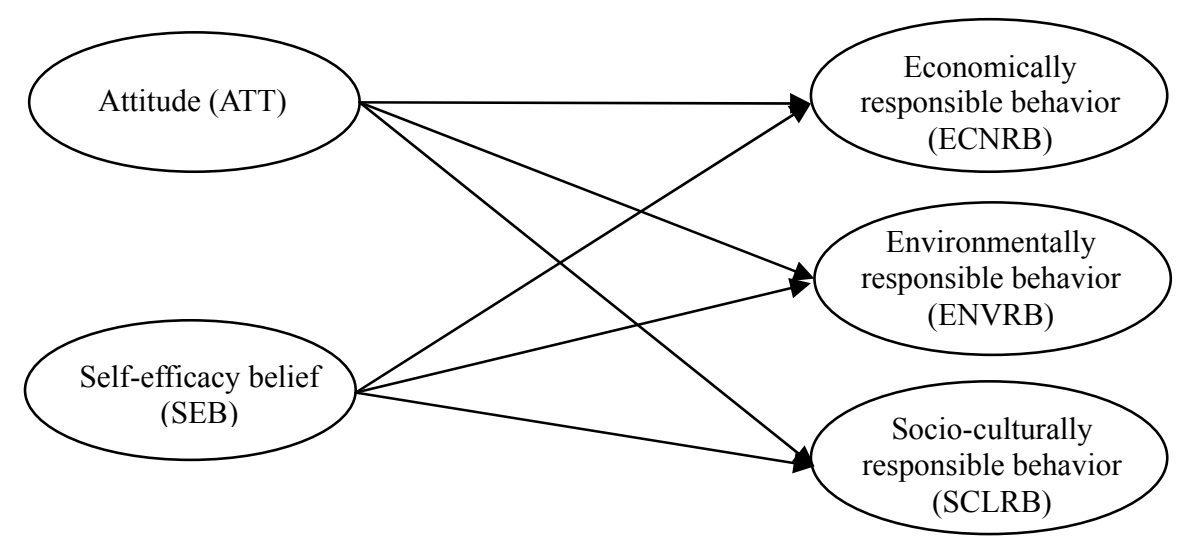

Figure 1. The initial conceptual model explaining the relationships among ATT, SEB, ECNRB, ENVRB, and SCLRB. 


\section{Methodology}

\section{Survey Design and Measurement}

Survey method is one of the commonly used transparent methods in leisure and tourism research (Veal, 2006) that explores standardized, quantifiable, and empirical data and facilitates a positivist stance (O'Leary, 2010). A self-administered questionnaire was employed in the survey. The questionnaire formulated the questions on two constructs of independent variables, namely: (1) attitude; and (2) self-efficacy through literature survey. In order to ensure the reliability, the constructs for independent variables were adapted from previous similar studies with some modifications in the wordings in individual item to fit into the context of the research as seen in Han et al. (2010) as well as in Song, You, Reisinger, C. Lee, and S. Lee (2014).

In the case of identifying dependent variables (RB practices), this research adapted a focus group approach as seen in Barr, Shaw, and Coles (2011) as well as in Liu and Tsaur (2014). The focus group was conducted at Begum Rokeya University, Rangpur, Bangladesh in August 2015 amongst professional MBA students with at least one holiday experience in the last two years. Following a 45-minute discussion, the group categorized nine kinds of responsible tourist behaviors into three groups, namely, ECNRB, ENVRB, and SCLRB that are noticed in Bangladesh.

Table 2

Questionnaire Constructs With Reference

Determinants of intentions (independent variables)

ATT 1: I would like to pay more for sustainable tourism products and services

ATT 2: As a tourist, I feel jointly responsible with others to protect the local natural and cultural environment

ATT 3: I obey local customs and laws whilst on my holiday

ATT 4: I would like to work for fellow tourists even when it becomes an expensive decision

ATT 5: I would like to patronize smaller tourism service providers

SEB 1: I study about a destination before visiting it

SEB 2: I am confident that I can personally make a difference in environmental protection through my behavior

SEB 3: I know how to spend my money to truly benefit the local economy that I visit

SEB 4: I can easily accept the customs of the local people in a destination

SEB 5: I know how to patronize the local art and culture of a destination that I visit

Responsible behavior (dependent variables)

ECN 1: I donate for the sanitation development of the destination I visit

ECN 2: I eat only local meals

ECN 3: I use local tourist guides

ENV 1: I mostly use public transport for traveling to tourist attractions

ENV 2: I stay off the usual tourist trail

ENV 3: I do not buy souvenir made from any elements of local flora and fauna

SCL 1: I wear local dress whilst visiting a destination

SCL 2: I volunteer for a destination's economic, environmental, and socio-cultural development

SCL 3: I learn the local language

Note. ATT = Attitude; SEB = Self-efficacy belief; ECN = Economic; ENV = Environmental; SCL = Socio-cultural.

In the initial questionnaire (see Table 2 above for the questionnaire constructs), both the constructs of independent variables (attitude and self-efficacy belief) were composed of five items and all the three constructs of dependent variables (ECNRB, ENVRB, and SCLRB) were composed of three items as suggested by Kline (2011) to use multiple items. Both the independent and dependent variables were measured on a 7-point Likert scale ranging from strongly disagree (1) to strongly agree (7). The questionnaire was written in 
both Bengali (the native language of Bangladesh) and English. After the pretest, which was conducted among 40 professionals with at least one holiday experience in the last two years, the variables that were not found significant at the 0.05 level in the correlation matrix (ATT 4 and SEB 4, ECN 1, ENV 1 and SCL 3, see Table 2) were removed from the final questionnaire as suggested by Field (2005). In addition to the above, one-sample T-test, Cronbach's Alpha, ANOVA with Tukey's test for nonadditivity, Hotelling's T-squared test, and KMO and Bartlett's test are measured and found significant at the 0.000 level (see Table 3 for the reliability statistics).

Table 3

Reliability Statistics of the Surveyed Data

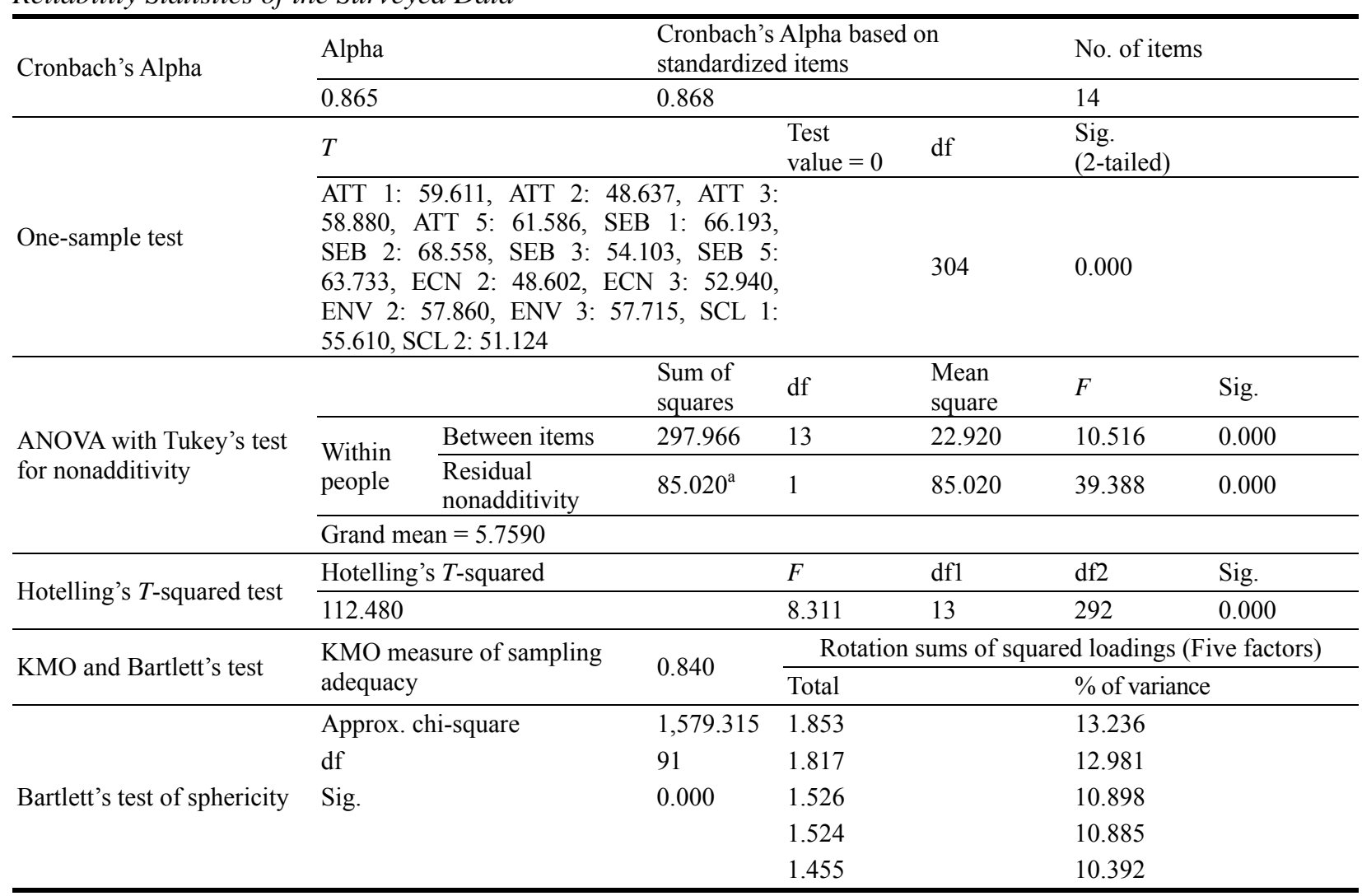

Note. ${ }^{\text {a }}$. Tukey's estimate of power to which observations must be raised to achieve additivity $=-1.865$.

\section{Sampling Frame and Data Collection}

In Bangladesh, the professional groups of both public and private sector employees as well as businessmen represent the majority of the domestic tourists, who enjoy a 2-10 days' holiday (Dey, Uddin, \& Hasan, 2013; Prince \& Khaleq, 2013). So, this segment of the domestic tourists was chosen for the survey. Although the elements of such sub-population are found in all the eight Divisional cities in Bangladesh for convenience, the Rangpur Divisional city was chosen as a cluster. Initially, the streets of the city were randomly selected; then, all households, businesses, and offices were also randomly selected. For this study, 400 questionnaires were distributed, after two days of the distribution, the distribute questionnaires were collected, but 305 questionnaires were received from the respondents with complete answers with a $76.25 \%$ return rate. Seven current MBA students of Begum Rokeya University, Rangpur, with some experience in conducting surveys and with good familiarity of the local roads in the city along with the researcher himself distributed the questionnaires in September 2015. After collecting the data, for analysis, IBM SPSS Version 22 and AMOS Version 21 were used. 


\section{Results and Discussion}

According to the results, the model is found a very good fit on some fit indices and excellent fit on some other fit indices in line with the contemporary researchers. It is found that both the independent variables and the dependent variables are very well set in their respective constructs (see Figure 2 to understand the impacts of independent variables on the dependent variables and also see Table 4 for the details). All the variables have squared multiple correlation well above of the usual norm (>0.20) (Byrne, 2010). Probability (P) is significant at $<0.01$ and the probability of the final model is $>0.05$ as suggested by Hooper, Coughlan, and Mullen (2008). In the case of the fit indices, the GFI is found $=\geq 0.95$ (as suggested by Miles \& Shevlin, 2007); AGFI is $=\geq 0.90$ (Byrne, 2010); TLI, IFI, and CFI $=\geq 0.95$ (Hu \& Bentler, 1999) and NFI $=\geq 0.90$ (Bentler \& Bonett, 1980). The root mean square error of approximation (RMSEA) in the model is $<0.07$ as suggested by Steiger (2007) and the critical ratio (CR) is $\geq 3.0$ according to Albright and Park (2009).

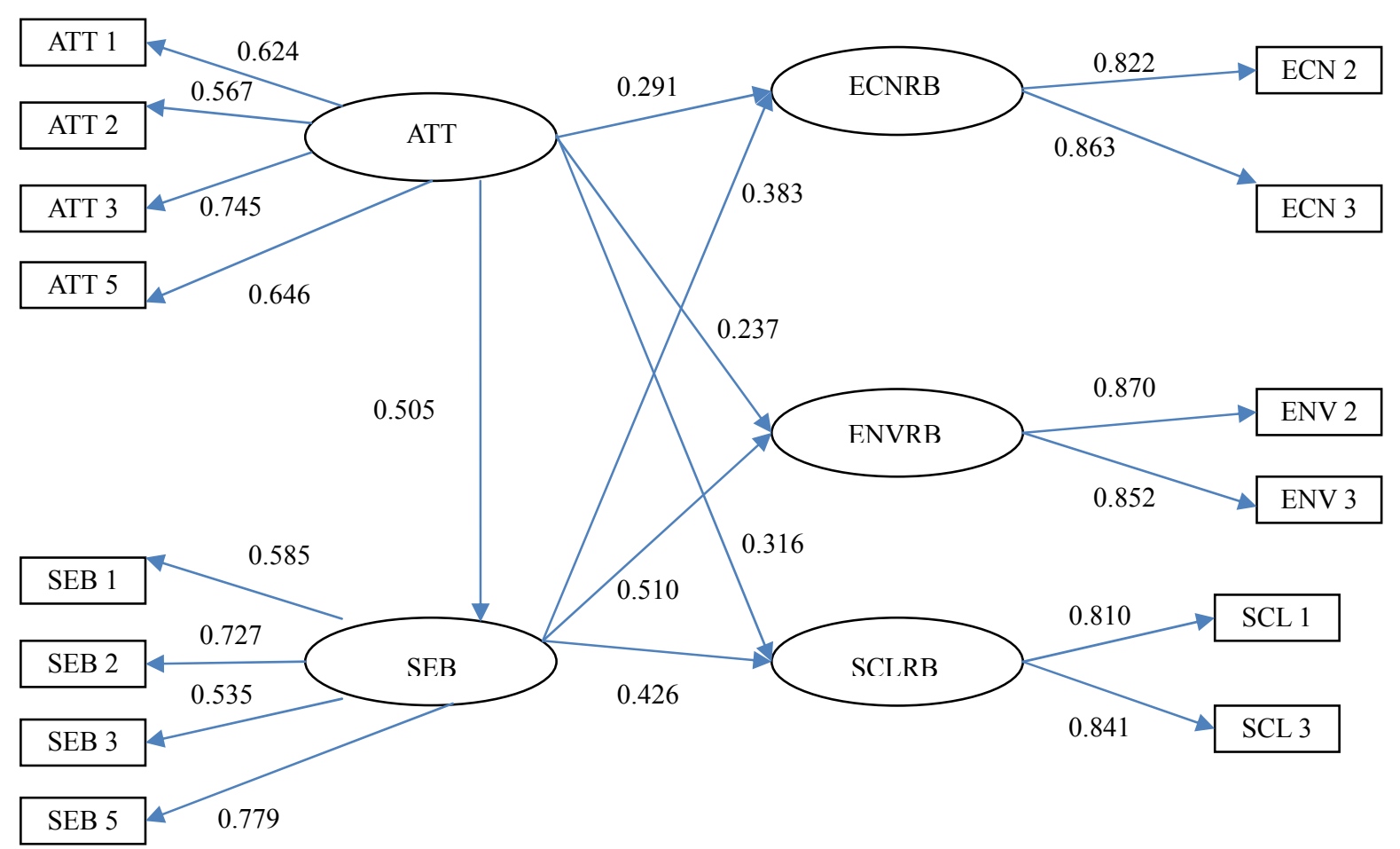

Figure 2. Final model with the standardized regression weights telling about the impacts of ATT and SEB on ECNRB, ENVRB, and SCLRB.

Although attitude to RB is being treated as a critical factor that influences the behavioral intention to behave responsibly (Schultz \& Oskamp, 1996), its influence varies between the intention to behave at home and on a holiday (Untaru et al., 2014). Relevant findings are found in the research of Diekmann and Preisendörfer (2003). They found that if a person perceives a particular behavior as low-cost and little inconvenience, then his or her positive attitude correlates significantly with the intention, but if it costs more and causes inconvenience, then the opposite scenario could be found. As in this research, tourists' attitude was found less effective than self-efficacy belief in predicting RB. So H1 (Hypothesis 1) initially assuming that attitude is the most influential determinant of intention to adopt RB is not true. 
Table 4

Details of the Confirmatory Factor Analysis and Path Model Statistics

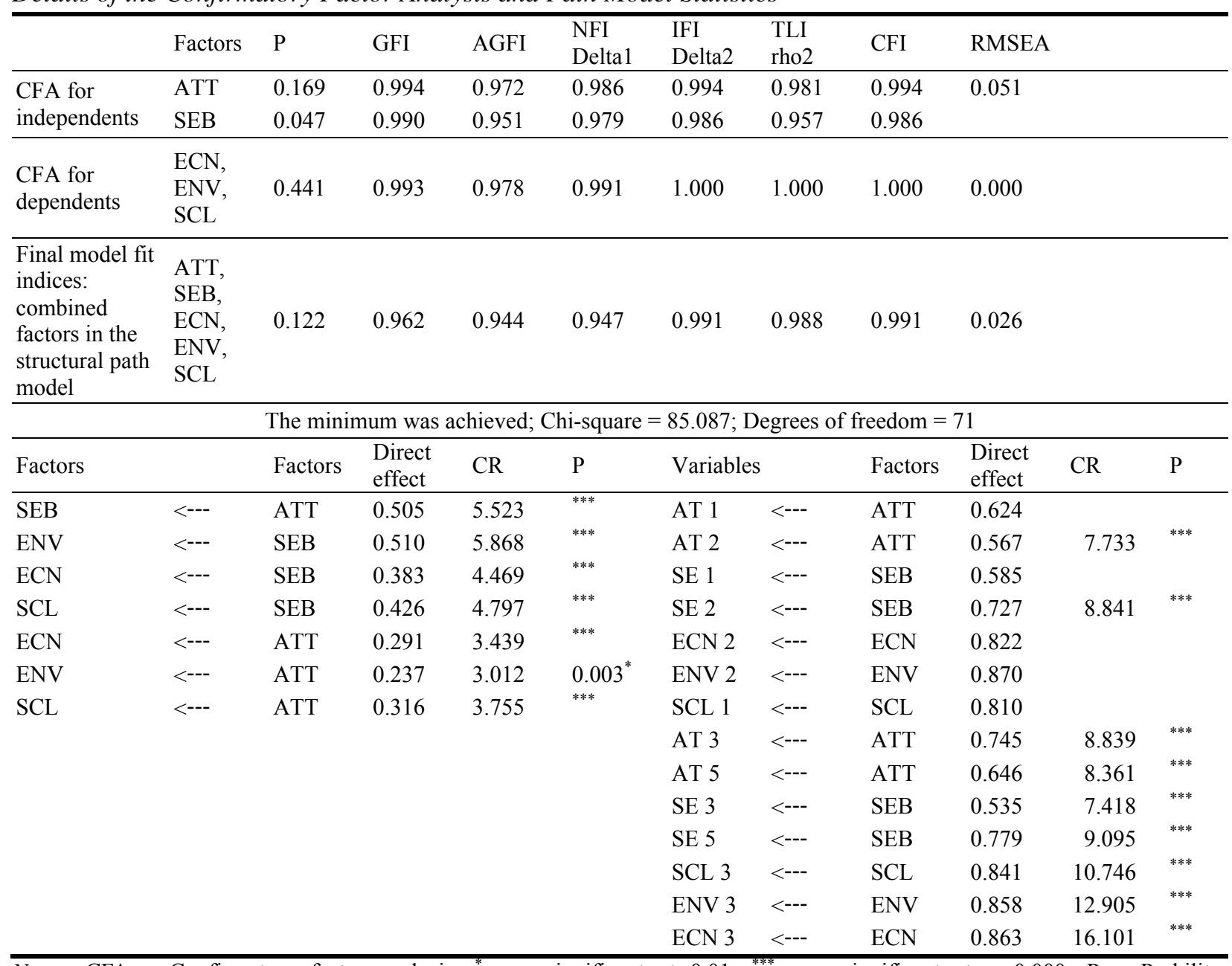

Notes. CFA $=$ Confirmatory factor analysis; ${ }^{*}=p$ significant at $0.01 ;{ }^{* * *}=p$ significant at $<0.000 ; \mathrm{P}=$ Probility; GFI = Goodness-of-fit index; AGFI = Adjusted goodness of fit index; TLI = Tucker-Lewis index; IFI = Incremental fit indices; $\mathrm{CFI}=$ Comparative fit index; NFI = Normed-fit index; RMSEA $=$ Root mean square error of approximation; $\mathrm{CR}=\mathrm{Critical}$ ratio.

Self-efficacy was found very important in the intention to choose alternatives as "high self-efficacious persons explore new things and choose to perform more challenging tasks than those with low self-efficacy" (Schwarzer \& Fuchs, 1995, p. 1). So, only a high self-efficacious person takes the challenges to consume certain environmentally and socially responsible goods and services (Ben-Ami et al., 2014). As this research found that self-efficacy belief is more effective in predicting RB than attitude, H2 (Hypothesis 2) initially assuming that self-efficacy belief is the most influential determinant of intention to adopt RB is true.

It is also found that among the three types of behavior, attitude influences intention more for choosing SCLRB than ECNRB and ENVRB. On the other hand, self-efficacy belief influences intention more for choosing ENVRB than SCLRB and ECNRB. So, H3 (Hypothesis 3) initially assuming that the influence of attitude and self-efficacy belief is varied while predicting ECNRB, ENVRB, and SCLRB is found true. One more finding from the research is that the ECNRB is less predicted by both the attitude and self-efficacy belief compared to ENVRB and SCLRB. This means that tourists have less intention to adopt ECNRB than ENVRB and SCLRB. 
Between the two ECNRB ("eating local meals" and "using local tourist guides"), tourists choose "using local tour guides" as the most responsible behavior than "eating local meals". Use of local tourist guide not only supports locals' life economically, but also helps them achieve sustainability in many aspects of tourism $(\mathrm{Hu}, 2007)$. The role of a local tour guide is very important in the case of ecotourism and nature-based tourism for building long-term environmental relationships between tourists and destinations (Tetik, 2016). Local tourist guides or on-site guides or special guides tell tourists about the authentic source of local foods, traditional events due to their in-depth local knowledge and thus they have multiple effects on a destination's promotion and development (Chilembwe \& Mweiwa, 2014). The use of a local tour guide is still less popular in Bangladesh, so for the sustainable tourism development, the use of local tour guides should be promoted by the tourism sector policy makers. Also, eating local meals by tourists contributes to local economic development, but finding out "local" meal requires time and effort for the tourists (Sims, 2009). Actually, the term "local" is very specific and includes meals that are produced using local ingredients and manufactured within the defined territory. Moreover, it is produced with tradition and naturalness and is not fake and transmits some authentic meanings about the place, people, and culture (Sims, 2009). So, the sustainable tourism promoter should help the tourists to find out local meal and having it to spread out the local destination's positive image.

In the case of ENVRB, between the two kinds of RB, tourists take "staying off the beaten track" more seriously than "not buying souvenirs made from the endangered species", for example, if tourists stay on an organic farm, eco cabin, or campsite, it takes them closer to the nature, home lifestyles, and simple living and helps to share the economic benefits of tourism with the local community and enjoy authentic experience, but keeping people and their culture as they are (Weeden, 2014, p. 83). It also facilitates tourists in learning local language and teaches their native language to the local people, makes true connections with the locals and experiences pure locality, for example, an English man while staying with a homestay family can do so (Reid, 2015). So for the sustainable development of tourism, tourists' intention to stay off the beaten track is of course an important issue. Tourists' intention to avoid buying souvenirs made from the endangered species is also a remarkable RB for tourists visiting many destinations. This kind of behavior has broad economic, environmental, and legal implications (Woronuk, 2008). In many cases, however, tourists who unwittingly buy souvenirs made from Ivory, tortoiseshell, reptile skins, furs and some corals and seashells, etc., while coming back home with such products in their luggage, are risking hefty fines or even jail sentences (Responsible Travel, n.d.). So both for the tourists and the destination community, this is also an important RB to be practiced by the tourists.

In the case of SCLRB, "volunteering for a destination's development" is chosen first, then "wearing local dress" by the tourists in Bangladesh. Voluntourists transfer needed skills, provide necessary funds, develop and feel human connection, add value to and provide benefit to others, bond the community for the volunteer and the wider world (Scott, 2016). The work of volunteer tourists has a great economic value (Solberg, 2003). Their work included but not limited to teaching language, developing community, organizing cultural and sports events, working on conservation, and working with children (Cousins, 2007). In developing countries like Bangladesh, this kind of volunteering activities is very much essential for the sustainable development of a tourism destination. Moreover, local dress promotes the originality of a destination. Local handmade woolen traditional dress has a great economic value (Carnaffan, 2014). This product benefits the locals more than the tourists by promoting local culture and tradition elsewhere and creates opportunity for local employment, reduces the conflict between the local tourism businesses and traditional community people, and keeps the culture and local tradition (Campbell, 2010). 
Among the nine RB alternatives identified in the focus group, "using public transport" and "learning the local language" insignificantly correlated with other RB alternatives in the pretest results. Public transport is already popular in Bangladesh and is the cheapest among all the different modes of transportation, so tourists found that this one is not a serious behavioral issue right now. Also in Bangladesh, seven regional languages (Faquire, 2012) and 16 tribal languages are spoken (Chowdhury, 2012) in addition to the national language, but the tourists less interact with these languages because the local people have a good access to the national language and therefore tourists do not consider this one a major RB. Donating to sanitation development is although an important issue in many destinations, for Bangladesh, it is not so severe right now. For example, Karmakar (2015) noted that Bangladesh achieved amazing success in sanitation in 15 years and now only $1 \%$ people used to defecate in the open, and the country is supposed to declare as a free from open defecation. Although these behaviors were not found important among the Bangladeshi tourists, they could be important in different countries, because tourists' RB varied significantly between countries and contexts (Stanford, 2008).

\section{Conclusions}

The aim of this empirical study was to generate insights into domestic tourists' intention to adopt RB. This research found that in Bangladesh, self-efficacy belief was found more important than attitude in predicting RB, but attitude can impact on the formation of self-efficacy belief that ultimately leads their intention to adopt RB. Also, the influence of attitude and self-efficacy belief on tourists' intention to adopt ECNRB, ENVRB, and SCLRB is varied. Finally, tourists are found to have less intention to adopt ECNRB than ENVRB and SCLRB.

These findings will help the policy makers to understand which determinants motivate tourists to adopt a certain type of behavior. So, if policy makers or promoters of RT want to promote any kind of behavior, they would be needed to address relevant motivators in their communication messages whilst targeting a particular tourist segment. For example, in the case of increasing self-efficacy belief, the promoter can highlight the contemporary tourists' positive experience in overcoming obstacles, their success, capabilities and confidence, the deep feeling of responsibility (Bandura, 1997), and "imaginable experiences" (showing that tourists behave properly in a given situation) (Maddux, 2005) in designing communications for different media.

However, besides the contribution of this study, it has some limitations that suggest future research in this regard. In this study, the respondents were professionals and graduates. Although this group represents the majority of holiday makers (2-10 days) in Bangladesh (Dey et al., 2013), there are other groups of people outside of this study who may affect tourism. This research used only attitude and self-efficacy belief as the determinant, however, many other determinants, for example, demographic factors, external factors, and internal factors, also affect the intention to adopt RB (Kollmuss \& Agyeman, 2002). So a broader research project could generate more insights into the future.

\section{References}

Albright, J., \& Park, H. (2009). Confirmatory factor analysis using Amos, LISREL, and Mplus, SAS/STAT CALIS. Working Paper, The University Information Technology Services (UITS) Center for Statistical and Mathematical Computing, Indiana University. Retrieved from http://www.indiana.edu/ statmath/stat/all/cfa/index.html

Atkins, R. (2010). What's it like to live with tourists? Guardian Travel Blog. Retrieved from http://www.theguardian.com/travel/blog/2010/apr/07/living-with-tourists-tourism

Bagozzi, R. P., \& Warshaw, P. R. (1990). Trying to consume. Journal of Consumer Research, 17(2), 127-140.

Ballantyne, R., Packer, J., \& Hughes, K. (2009). Tourists' support for conservation messages and sustainable management practices in wildlife tourism experiences. Tourism Management, 30(5), 658-664. 
Bandura, A. (1997). Self-efficacy: The exercise of control. New York, NY: Freeman.

Barr, S., Shaw, G., \& Coles, T. (2011). Times for (un)sustainability? Challenges and opportunities for developing behaviour change policy. A case-study of consumers at home and away. Global Environmental Change, 21(4), 1234-1244.

Bay, D., \& Daniel, H. (2003). The theory of trying and goal-directed behavior: The effect of moving up the hierarchy of goals. Psychology \& Marketing, 20(8), 669-684.

Ben-Ami, M., Hornik, J., Eden, D., \& Kaplan, O. (2014). Boosting consumers' self-efficacy by repositioning the self. European Journal of Marketing, 48(11/12), 1914-1938.

Bentler, P. M., \& Bonett, D. G. (1980). Significance tests and goodness of fit in the analysis of covariance structures. Psychological Bulletin, 88(3), 588-606.

Budeanu, A. (2007). Sustainable tourist behaviour - A discussion of opportunities for change. International Journal of Consumer Studies, 31(5), 499-508.

Burns, P. (2000). An introduction to tourism and anthropology. London: Routledge.

Byrne, B. (2010). Structural equation modeling with AMOS: Basic concepts, applications, and programming (2nd ed.). London: Routledge.

Campbell, A. (2010). Strategic destination marketing, Nagigi style: Olivia's homestay in Fiji. In A. Lewis-Cameron, \& S. Roberts (Eds.), Marketing Island destinations: Concepts and cases. London: Elsevier, Inc..

Cape Town Conference. (2002). Cape Town declaration: Cape Town conference on responsible tourism in destinations. Organization Studies, 29, 1495-1519.

Carnaffan, J. (2014). Rural tourism as a tool of regional development: A multi-scalar analysis of responsible, home stay tourism in Rural Peru. In K. Dashper (Ed.), Rural tourism: An international perspective. Newcastle upon Tyne: Cambridge Scholars Publishing.

Caruana, R., Glozer, S., Crane, A., \& McCabe, S. (2014). Tourists' accounts of responsible tourism. Annals of Tourism Research, 46, 115-129.

Cater, E. (1993). Ecotourism in the third world: Problems for sustainable tourism development. Tourism Management, 14(2), 85-90.

Chafe, Z. (2005). Consumer demand and operator support for socially and environmentally responsible tourism. Washington: CESD/TIES. Retrieved from http://www.rainforest-alliance.org/branding/documents/consumer_demand.pdf

Chilembwe, J. M., \& Mweiwa, V. (2014). Tour guides: Are they tourism promoters and developers? Case study of Malawi. IMPACT: International Journal of Research in Business Management, 2(9), 29-46.

Chowdhury, A. (2012). Tribal languages. Banglapedia. Retrieved from http://en.banglapedia.org/index.php?title=Tribal_Languages

Cousins, J. A. (2007). The role of UK-based conservation tourism operators. Tourism Management, 28(4), 1020-1030.

CREST. (2009). The market for responsible tourism products: With a special focus on Latin America and Nepal. Retrieved from http://www.responsibletravel.org/resources/documents/reports/The\%20Market\%20for\%20Responsible\%20Tourism\%20Products.pdf

Dey, P., Uddin, S., \& Hasan, K. (2013). Tourists' perception towards Cox's Bazar sea beach in Bangladesh as a tourist destination. Asian Business Review, 2(1/3), 54-60.

Diekmann, A., \& Preisendörfer, P. (2003). Green and greenback: The behavioral effects of environmental attitudes in low-cost and high-cost situations. Rationality and Society, 15(4), 441-472.

Doran, R., Hanss, D., \& Larsen, S. (2015). Attitudes, efficacy beliefs, and willingness to pay for environmental protection when travelling. Tourism and Hospitality Research, $0(0), 1-12$.

Faquire, A. B. M. (2012). On the classification of varieties of Bangla spoken in Bangladesh. Bup Journal, 1(1), 130-139.

Ferdaush, J., \& Faisal, H. (2014). Tourism potentiality \& development of Bangladesh: Applicability of pragmatic governmental management policy. Journal of Management and Science, 4(1), 71-78.

Field, A. (2005). Discovering statistics using SPSS (2nd ed.). London: Sage Publications.

Fishbein, M., \& Ajzen, I. (2010). Predicting and changing behavior: The reasoned action approach. New York, NY: Psychology Press.

Goodwin, H. (2011). Taking responsibility for tourism. London: Goodfellow Publishers.

Goodwin, H., \& Pender, L. (2005). Ethics in tourism management. In L. Pender, \& R. Sharpley (Eds.), The management of tourism (pp. 288-304). London: Sage Publications.

Grimwood, B. S. R., Yudina, O., Muldoon, M., \& Qiu, J. (2015). Responsibility in tourism: A discursive analysis. Annals of Tourism Research, 50, 22-38.

Han, H., \& Kim, Y. (2010). An investigation of green hotel customers' decision formation: Developing an extended model of the theory of planned behavior. International Journal of Hospitality Management, 29(4), 659-668. 
Han, H., Hsu, L., \& Sheu, C. (2010). Application of the theory of planned behavior to green hotel choice: Testing the effect of environmental friendly activities. Tourism Management, 31(3), 325-334.

Hassan, M. M., \& Shahnewaz, M. (2014). Measuring tourist service satisfaction at destination: A case study of Cox's Bazar sea beach, Bangladesh. American Journal of Tourism Management, 3(1), 32-43.

Honeck, D., \& Akhtar, M. (2014). Achieving Bangladesh's tourism potential: Linkages to export diversification, employment generation and the "green economy". Staff Working Paper ERSD-2014-15: World Trade Organization Economic Research and Statistics Division.

Hooper, D., Coughlan, J., \& Mullen, M. (2008). Structural equation modelling: Guidelines for determining model fit. Electronic Journal of Business Research Methods, 6(1), 53-60.

Hu, L., \& Bentler, P. M. (1999). Cutoff criteria for fit indexes in covariance structure analysis: Conventional criteria versus new alternatives. Structural Equation Modeling, 6(1), 1-55.

Hu, W. (2007). Tour guides and sustainable development: The case of Hainan, China (Ph.D. thesis, Waterloo, Ontario, Canada).

Hudson, S., \& Ritchie, B. (2001). Cross-cultural tourist behavior: An analysis of tourist attitudes towards the environment. Journal of Travel \& Tourism Marketing, 10(2-3), 1-22.

Husbands, W., \& Harrison, L. C. (1996). Practicing responsible tourism: Understanding tourism today to prepare for tomorrow. In L. C. Harrison, \& W. Husbands (Eds.), Practicing responsible tourism: International case studies in tourism planning, policy and development. New York, NY: John Wiley \& Sons.

Ibtissem, M. H. (2010). Application of value beliefs norms theory to the energy conservation behaviour. Journal of Sustainable Development, 3(2), 129-139.

Jarvis, T. (2013). Sustainable tourism and its potential for Sri Lanka (Master thesis, University of Worcester).

Karmakar, A. (2015). Amazing success of Bangladesh in sanitation. Prothom Alo. Retrieved from http://en.prothom-alo.com/bangladesh/news/81351/Amazing-success-of-Bangladesh-in-sanitation

Kline, R. B. (2011). Principles and practice of structural equation modeling (3rd ed.). London: The Guilford Press.

Kollmuss, A., \& Agyeman, J. (2002). Mind the gap: Why do people act environmentally and what are the barriers to pro-environmental behavior? Environmental Education Research, 8(3), 239-260.

Lea, J. P. (1993). Tourism development ethics in the third world. Annals of Tourism Research, 20(4), 701-715.

Lee, T. H. (2009). A structural model to examine how destination image, attitude, and motivation affect the future behavior of tourists. Leisure Sciences: An Interdisciplinary Journal, 31(3), 215-236.

Lee, T., Jan, F., \& Yang, C. (2013). Conceptualizing and measuring environmentally responsible behaviors from the perspective of community-based tourists. Tourism Management, 36, 454-468.

Leslie, D. (2012a). The responsible tourism debate. In D. Leslie (Ed.), Responsible tourism: Concepts, theory and practice (pp. 17-42). Wallington: CABI.

Leslie, D. (2012b). The consumers of tourism. In D. Leslie (Ed.), Responsible tourism: Concepts, theory and practice (pp. 54-71). Wallington: CABI.

Liu, J., \& Tsaur, S. (2014). We are in the same boat: Tourist citizenship behaviors. Tourism Management, 42, 88-100.

Maddux, J. E. (2005). Self-efficacy: The power of believing you can. In C. R. Snyder, \& S. J. Lopez (Eds.), Handbook of positive psychology. New York, NY: Oxford University Press.

Mann, M. (2000). The community tourism guide: Exciting holidays for responsible travellers. London: Earthscan.

Mathur, A. (1998). Examining trying as a mediator and control as a moderator of intention-behavior relationship. Psychology \& Marketing, 15(3), 241-259.

Miles, J., \& Shevlin, M. (2007). A time and a place for incremental fit indices. Personality and Individual Differences, 42(5), 869-874.

Moscardo, G., Konovalov, E., Murphy, L., \& McGehee, N. (2013). Mobilities, community well-being and sustainable tourism. Journal of Sustainable Tourism, 21(4), 532-556.

O'Leary, Z. (2010). The essential guide to doing your research project. London: Sage Publications.

O’Sullivan, D., \& Jackson, M. J. (2002). Festival tourism: A contributor to sustainable local economic development? Journal of Sustainable Tourism, 10(4), 325-342.

Parveen, J. (2013). Current status of tourism industry in Bangladesh: An empirical evaluation. Scientific Research Journal (SCIRJ), 1(1), 41-57.

Prince, P., \& Khaleq, Z. (2013). Assessment of gap between service quality expectation and perception: A study on the walk-in guests of economic hotels in Cox's Bazar, Bangladesh. The IUP Journal of Marketing Management, 12(3), 7-26. 
Reid, P. (2015). The advantages of staying with a homestay family. Retrieved from https://taiken.co/single/the-advantages-of-staying-with-a-homestay-family

Responsible Travel. (n.d.). About to go on holiday? Think twice about your souvenirs. Responsible Travel. Retrieved from $\mathrm{http}$ //www.responsibletravel.com/copy/about-to-go-on-holiday-think-twice-about-your-souvenirs

Sandve, A., Marnburg, E., \& Øgaard, T. (2014). The ethical dimension of tourism certification programs. International Journal of Hospitality Management, 36, 73-80.

Schultz, P. W., \& Oskamp, S. (1996). Effort as a moderator of the attitude-behavior relationship: General environmental concern and recycling. Social Psychology Quarterly, 59(4), 375-383.

Schwarzer, R., \& Fuchs, R. (1995). Self-efficacy and health behaviours. In M. Conner, \& P. Norman (Eds.), Predicting health behaviour: Research and practice with social cognition models. Buckingham: Open University Press.

Scott, A. (2016). Volunteering and voluntourism: The good, the bad, and the questions you should ask. Uncornered market. Retrieved from http://uncorneredmarket.com/volunteering-voluntourism-good-bad-and-questions-to-ask/

Sharpley, R. (2010). The myth of sustainable tourism. CSD Working Papers Series 2009/2010 - No. 4. Centre for Sustainable Development (CSD), University of Central Lancashire. Retrieved from https://ysrinfo.files.wordpress.com/2012/06/csd_working_paper_4_sustainable_tourism_sharpley.pdf

Sheppard, B. H., Hartwick, J., \& Warshaw, P. R. (1988). The theory of reasoned action: A meta-analysis of past research with recommendations for modifications and future research. Journal of Consumer Research, 15(3), 325-343.

Simon, G. L., \& Alagona, P. S. (2009). Beyond leave no trace. Ethics, Place and Environment, 12(1), 17-34.

Sims, R. (2009). Food, place and authenticity: Local food and the sustainable tourism experience. Journal of Sustainable Tourism, 17(3), 321-336.

SNV. (2011). The responsible travel market in Cambodia: A scoping study. Retrieved from http://www.snvworld.org/download/publications/the_responsible_travel_market_in_cambodia.pdf

Solberg, H. A. (2003). Major sporting events: Assessing the value of volunteers' work. Managing Leisure, 8(1), 17-27.

Som, A. P. M., Marzuki, A., Yousefi, M., \& AbuKhalifeh, A. N. (2012). Factors influencing visitors' revisit behavioral intentions: A case study of Sabah, Malaysia. International Journal of Marketing Studies, 4(4), 39-50.

Song, H., You, G., Reisinger, Y., Lee, C., \& Lee, S. (2014). Behavioral intention of visitors to an oriental medicine festival: An extended model of goal directed behavior. Tourism Management, 42, 101-113. doi: 10.1016/j.tourman.2013.11.003

Stanford, D. (2008). "Exceptional visitors": Dimensions of tourist responsibility in the context of New Zealand. Journal of Sustainable Tourism, 16(3), 258-275.

Steiger, J. H. (2007). Understanding the limitations of global fit assessment in structural equation modeling. Personality and Individual Differences, 42(5), 893-898.

Tearfund. (2000a). Tearfund guide to tourism: Don't forget your ethics. Tearfund.

Tearfund. (2000b). Tourism - An ethical issue: Market research report. Glasgow: Tearfund.

Tetik, N. (2016). The importance of interpretation role of tour guides in geotourism: Can we called them as geotour guides? International Journal of Education and Social Science, 3(2), 41-53.

Tixier, M. (2010). Tourism at the crossroads of economic, social and environmental considerations. The International Journal of Management and Business, 1(1), 103-126.

Untaru, E. N., Epuran, G., \& Ispas, A. (2014). A conceptual framework of consumers' pro-environmental attitudes and behaviours in the tourism context. Bulletin of the Transilvania University of Braşov. Series V: Economic Sciences, 7(2), 85-94.

Veal, A. J. (2006). Research methods for leisure and tourism: A practical guide. London: Pearson Education, Ltd..

Weeden, C. (2014). Responsible tourist behaviour. London: Routledge.

Woronuk, J. A. (2008). Tourists' awareness, attitudes, and perceptions of wildlife souvenirs: A case study in Cuba (Master thesis, University of Waterloo, Ontario, Canada).

Wurzinger, S. (2003). Are ecotourists really more "eco"? A comparison of general environmental beliefs, specific attitudes, general ecological behaviour, and knowledge between Swedish ecotourists and non-ecotourists. Lund: Lund University, School of Architecture.

Xie, C., Bagozzi, R. P., \& Troye, S. V. (2008). Trying to prosume: Toward a theory of consumers as co-creators of value. Journal of the Academy of Marketing Science, 36(1), 109-122.

Zahra, I. (2013). Tourism and its impact on Cox's Bazar, Bangladesh. Journal of Tourism, 15, 12-18. 